\title{
THE
}

\section{The Dynamics of House Price Responsiveness and Locational Sorting: Evidence from Air Quality Changes}

Corey Lang

University of Rhode Island, clang@uri.edu

Follow this and additional works at: https://digitalcommons.uri.edu/enre_facpubs

The University of Rhode Island Faculty have made this article openly available.

Please let us know how Open Access to this research benefits you.

This is a pre-publication author manuscript of the final, published article.

Terms of Use

This article is made available under the terms and conditions applicable towards Open Access Policy Articles, as set forth in our Terms of Use.

\section{Citation/Publisher Attribution}

Lang, Corey. (2015). "The dynamics of house price responsiveness and locational sorting: Evidence from air quality changes." Regional Science and Urban Economics. Available at: http://dx.doi.org/10.1016/ j.regsciurbeco.2015.02.005

This Article is brought to you for free and open access by the Environmental and Natural Resource Economics at DigitalCommons@URI. It has been accepted for inclusion in Environmental and Natural Resource Economics Faculty Publications by an authorized administrator of DigitalCommons@URI. For more information, please contact digitalcommons-group@uri.edu. 


\title{
THE DYNAMICS OF HOUSE PRICE RESPONSIVENESS AND LOCATIONAL SORTING: EVIDENCE FROM AIR QUALITY CHANGES
}

\author{
Corey Lang \\ Department of Environmental and Natural Resource Economics \\ University of Rhode Island \\ clang@uri.edu
}

January 8, 2015

\begin{abstract}
Despite extensive use of housing data to reveal valuation of non-market goods, the process of house price adjustment remains vague. Using the restricted access American Housing Survey, a high-frequency panel of prices, turnover, and occupant characteristics, this paper examines the time path of prices and preference-based sorting in response to air quality changes caused by differential regulatory pressure from the 1990 Clean Air Act Amendments. The results suggest that owner-occupied units capitalize changes quickly, whereas rent prices lag behind amenity levels. The delayed but sharp rent response temporally coincides with evidence of sorting, indicating a strong link between location choices and price dynamics.
\end{abstract}

JEL codes: R23, R31, Q51, Q53

Keywords: hedonic valuation, price dynamics, capitalization, sorting, air quality

Thanks to Ian Schmutte for assistance with the RDC proposal, to seminar participants at Cornell University, University of Colorado-Denver, University of Connecticut, University of Tennessee, Williams College, EPA-NCEE, CES, AERE 2012, and UEA 2012, and to Kevin Roth, Wouter Vermeulen, Andrew Waxman and two anonymous referees for valuable comments. Special thanks to Antonio Bento and Matthew Freedman for guidance and suggestions throughout this project. This paper is a contribution of the Rhode Island Agricultural Experiment Station (\#5363). Any opinions and conclusions expressed herein are those of the author and do not necessarily represent the views of the U.S. Census Bureau. All results have been reviewed to ensure that no confidential information is disclosed. 


\section{INTRODUCTION}

Charles Tiebout (1956) argued that households should "vote with their feet” and choose residential locations with the optimal bundle of amenities and price. Since that time, and especially after Rosen’s (1974) formal development of hedonic theory, hedonic valuation has become a workhorse model among economists - Google Scholar reports over 30,000 articles using or discussing the method. ${ }^{1}$ This impressive level of application is justifiable given that housing market data can be used to uncover people's preferences and values for a wide range of spatially delineated non-market goods including school quality, crime, open space, and air pollution.

Despite the extensive use of housing data to reveal valuation of non-market goods, the process of house price adjustment remains vague. Hedonic theory is based on equilibrium; the compensating differential in housing prices across locations reflects the value of amenity differences, such that the marginal mover is indifferent between locations. Rosen's model assumes costless relocation, which most empirical applications extend to indicate immediate price responses reflecting the changed amenity. Of course this assumption does not reflect reality, and our understanding of how prices and households dynamically respond to a change in amenity levels is limited. Further, the extent to which housing market dynamics impact the resulting valuation estimates is unknown. A study with a short time span could produce biased estimates of the amenity value due to insufficient time for price adjustment. A study with a long time span may also produce biased estimates if important determinants of house prices, which change on the time span of a decade but not one or two years, are unobserved and correlated with amenity changes.

This paper addresses these dynamic extensions of Tiebout's ideas in the context of large improvements in air quality that occurred in the United States during the 1990s. Specifically, I examine the path of prices for both owners and renters in response to a change in air quality going beyond if prices change to how prices change - and assess how these price response patterns may bias valuation estimates. Further, I analyze preference-based sorting and seek to understand the links between sorting behavior and price dynamics.

\footnotetext{
1 The search term was "hedonic valuation" excluding "wage” and "labor”, and the counts were as of August 21, 2014.
} 
The keystone of addressing these questions is the American Housing Survey (AHS), which collects information from a nationally representative panel of housing units and their occupants every two years, including self-reported home value or rent. The high frequency and regularity of observations is essential for examination of price dynamics and sorting, and no other non-proprietary data offers this. ${ }^{2}$ I match housing units from the AHS to particulate matter $\left(\mathrm{PM}_{10}\right)$ concentrations measured from nearby air quality monitors, and I exploit the structure of the 1990 Clean Air Act Amendments (CAAA) to identify quasi-exogenous variation in $\mathrm{PM}_{10}$. Similar to the seminal work of Chay and Greenstone (2005), I employ an Instrumental Variables (IV) strategy that relies on non-attainment designations of the air quality standards to address the endogenous relationship between air quality and housing prices.

Importantly, I gained access to the confidential version of the AHS through a Census Restricted Data Center. Unlike the public use AHS, which only identifies the geographic location of a housing unit at the MSA level, the confidential version identifies the census tract where each unit is located. This fine scale enables two critical aspects of the present research. First, the air quality that a given household faces can be measured with far greater precision. Second, the IV identification strategy can exploit localized air quality regulation intensity stemming from within-MSA differential regulatory pressure, which Auffhammer et al. (2009) show is the principal factor determining reductions in $\mathrm{PM}_{10}$.

The results suggest that while both owner and renter prices are responsive to air quality changes, the path of prices markedly differs. Owner-occupied housing units capitalize changes in air quality immediately, and capitalization rates and elasticities stay fairly constant across time. On the other hand, renter-occupied housing units show statistically insignificant and economically small price responses shortly after air quality changes, but the estimated valuation sharply increases at a lag of six years and continues to increase after that. Ten years after air quality began to change, estimated price elasticities are comparable to the owner-occupied units. Tests of statistical differences support the ideas that rental price responses increase over time and

\footnotetext{
${ }^{2}$ Additionally, the structure of the AHS obviates standard concerns when estimating a hedonic model. First, the omission of unobserved unit or location characteristics commonly biases hedonic estimates. The AHS offers multiple observations for each housing unit and thus time-invariant omitted variables do not pose a problem. When using sales data, researchers often rely on repeat sales to purge these time-invariant confounders. However, a repeat sales model can exclude as much as $97 \%$ of observations (Case and Quigley 1991). Further, transacting properties are not random; Case, Pollakowski, and Wachter (1997) show that properties that transact more tend to appreciate more, as well as have different structural characteristics. Appreciation estimates from the AHS will not have this same bias since all units report price changes, not just those that sell, and the units are randomly sampled.
} 
that short-term price responses are different for owners and renters, though with the later point, the evidence is mixed. This suite of results is robust to controlling for sample selection and controlling for pre-treatment price trends.

Several hypotheses are examined that could explain why rental prices lag behind amenity changes, including rental market rigidities, like rent control, and disparities in the characteristics of people and units that rent versus own. However, in each case the results maintain their pattern. Speculatively, the disparities in price response patterns could be due to owners being more attentive of amenity levels given their anticipated tenure and financial stake in the property. Interestingly, adjustment costs of moving, which are substantially larger for owners, appear not to be a factor affecting price dynamics.

The results support the idea that the owner and renter market are fairly distinct. Disparities between the two markets have already been documented in terms of the occupants and housing stock by Glaeser and Gyourko (2007), but demonstrating disparities in price dynamics is new. The different patterns of price responses lead to arbitrage opportunities between the owner and renter market purely based on air quality. However, at a maximum the disparity in annual housing costs is about $\$ 600$, which is unlikely to be enough for households to delay home purchase and certainly not enough to cover the financial costs of selling a home in order to be a renter. In sum, the price response results lend credence to the hedonic method for owner data, but suggest caution with renter data. For renters, the immediate price response is about one tenth of the eventual price response, suggesting substantial bias with the hedonic method if too short of a time interval is chosen.

The striking price dynamics observed in the rental market offer an excellent opportunity to examine the interplay between valuation and preference-based sorting. I analyze changes in turnover and demographic variables related to age, race, education, and income in response to changes in air quality. The results suggest that neighborhoods that experience improvements in air quality see an increase in the turnover frequency and the likelihood of families with children moving in relative to other neighborhoods, but only at a lag of six or more years. Thus, the results indicate a temporal correspondence between price dynamics and preference-based sorting and offer a strong empirical confirmation of Tiebout's ideas.

There are three main contributions of this paper. The first is to shed new light on how housing prices respond to a change in amenities. Despite extensive use of hedonic valuation, 
very few papers have addressed the dynamic details of price responses. ${ }^{3}$ Blanchard and Katz (1992) find that house prices decline after a negative shock to employment, but rebound faster than employment levels. Cellini et al. (2010) examine the effect of school spending from bond passage on house price sales. Their results suggest that capitalization rates tend to increase for two to three years following a bond and then stabilize, likely reflecting the trend that spending ramps up for three to four years following the referendum and then declines. Together, my results and others' agree that owner-occupied capitalization is quick, even for different amenities for which residents may have different preferences for and information about.

Second, I go beyond looking at the owner market, as Cellini et al. have done, and examine the dynamics of rental price responses as well. This aspect complements several recent papers that examine price responses for owner and renter units separately: Grainger (2012) and Bento et al. (2014) assess the distributional impacts of the 1990 CAAA and Davis (2011) examines the housing market impacts of new power plants. Each paper finds that rental prices are responsive to amenity changes, but less so than their owner-occupied counterparts. However, each of these papers use decennial census data, and thus only address differences in levels of price responses, whereas I employ the high frequency AHS to investigate differences in patterns of price adjustments. Interestingly, in a cross sectional setting, Banzhaf and Farooque (2013) and Winters (2012) both find that rental prices are more correlated with public goods and quality of life than owner values, which raises the possibility that rents better reflect amenity preferences in equilibrium. In contrast, my results suggest that when amenities are changing rapidly owner values better capture preferences.

Third, this paper complements prior work on the links between price response and preference-based sorting. ${ }^{4}$ Sieg et al. (2004) and Bayer et al. (2007) examine how general equilibrium effects can be substantially larger than direct effects of an amenity differential alone because of correlated preferences for the amenity in question and other neighborhood "goods”. For example, wealthy households locate in good school districts and their presence further causes house prices to appreciate because people want to live near them. The limitation of these papers

\footnotetext{
${ }^{3}$ Figlio and Lucas (2004) and Pope (2008) are additional papers that examine the responsiveness of house prices. Both papers examine changing information, not changing amenities, and find that prices are quick to respond to new information.

${ }^{4}$ Other prominent papers that examine preference-based sorting include: Cameron and McConnaha (2006) and Greenstone and Gallagher (2008) in response to Superfund cleanups; Cellini et al. (2010) for school quality; Card et al. (2008) for racial preferences; and Banzhaf and Walsh $(2008,2013)$ for toxic emissions.
} 
is that they rely on cross sectional identification and thus do not actually observe sorting dynamics, only an equilibrium snapshot. The benefit of my partial equilibrium approach is that I do observe dynamic sorting behavior in response to quasi-exogenous amenity changes and find that prices and sorting are dynamically linked. The limitation of my approach, however, is that I cannot distinguish direct versus indirect valuation. It is possible that the true valuation of air quality for renters is zero, as reflected in the short term unresponsiveness of prices, and the rapid increase in prices several years later is not due to air quality but due to preferences for living near the new types of people moving into the cleaned up areas. However, given that the sorting analysis indicates that income, race and education levels (which are the key drivers of social multipliers in Bayer et al.) do not change on average between old and new occupants, it seems less likely that the delayed price response is greatly affected by social multipliers and is thus likely a good indication of direct preferences for air quality for renters.

The paper proceeds as follows. The next section describes the setting in which I examine price response patterns and the use of the CAAA as a quasi-experiment. Section 3 discusses data, including summary statistics comparing renters to owners and treated to untreated. Sections 4 and 5 present the price response results and the sorting results, respectively. Section 6 concludes.

\section{The 1990 Clean Air Act Amendments as A QuAsi-ExPERIMENT}

\subsection{Background on Particulate Matter and the 1990 Clean Air Act Amendments}

Particulate matter is a class of solid and liquid air pollutants that consists of nitrates, organic chemicals, metals, soot, smoke, and dust. Particulate matter enters the atmosphere either directly from a source, such as construction sites, unpaved roads, fields, smokestacks or fires, or indirectly as the result of reactions from sulfur dioxides and nitrogen oxides that are emitted from power plants, industrial facilities, or motor vehicles (Unites States Environmental Protection Agency [EPA] 2010). In general, the contribution of indirect sources is substantially larger to overall particulate matter concentrations than the contribution of direct sources.

Particulate matter is classified by the measurement of its diameter, with the diameter being inversely related to the potential for human health damage. $\mathrm{PM}_{10}$, the pollutant of interest in this paper, is particulate matter that is less than 10 micrometers in diameter. At this diameter, particulate matter can penetrate deeply into the human respiratory system and cause numerous health problems, including aggravated asthma, chronic bronchitis, and even premature death for 
those with pre-existing lung and heart problems (EPA 2010). ${ }^{5}$

Responding to calls for action and mounting scientific evidence, the United States Congress passed the 1970 CAA, which was the first federal legislation establishing air quality control. ${ }^{6}$ The 1970 CAA created the EPA and authorized it to enforce National Ambient Air Quality Standards (NAAQS) for six common air pollutants, the so-called criteria pollutants. Particulate matter was included in this group in the form of total suspended particulates, or TSPs, which is particulate matter of diameter 100 micrometers or less. The 1990 CAAA, the second major update of the CAA, replaced TSPs with $\mathrm{PM}_{10}$ to parallel current scientific understanding of pollution's effects. ${ }^{7}$

The objective of the NAAQS was to lower concentrations of the criteria pollutants below harmful levels everywhere in the United States. For $\mathrm{PM}_{10}$, the EPA set an annual arithmetic mean daily readings concentration threshold of $50 \mu \mathrm{g} / \mathrm{m}^{3}$ and a 24-hour arithmetic mean concentration threshold of $150 \mu \mathrm{g} / \mathrm{m}^{3}$. ${ }^{8}$ In order to achieve the NAAQS, the EPA held counties and states accountable for meeting those standards. Importantly, if even a single monitor within a county exceeds the annual threshold or the 24-hour threshold for more than one day, then the entire county is considered in violation of the standard. The EPA can then move to designate that county as out of attainment, which then requires the county and state, in cooperation with the EPA, to develop an official plan to reduce pollution and attain the standards set forth by the NAAQS. As a means to encourage compliance, non-attainment counties can be subject to scrutiny over industrial activities, including the opening of new plants, and can even have federal highway funds withheld.

\footnotetext{
${ }^{5}$ For a concise analysis of the health effects from exposure to PM10, see Hall et al. (1992), Dominici et al. (2002), and Daniels et al. (2000). In addition to human health effects, particulate matter damages crops and buildings and reduces visibility (EPA 2010).

${ }^{6}$ Prior federal legislation in the 1950s and 1960s merely provided funds for monitoring air quality and for research on the impacts of pollution on health and agriculture (EPA 2010).

${ }^{7}$ In addition, the 1990 CAAA expanded the scope of federal regulation by adding control over the release of 189 toxic chemicals and by initiating the Acid Rain Program. In 1997, the EPA further refined the NAAQS to target $\mathrm{PM}_{2.5}$, again reflecting current understanding.

${ }^{8}$ The EPA sets primary and secondary standards for all criteria pollutants, where primary standards address human health, especially of vulnerable populations, and secondary standards address overall human welfare. For $\mathrm{PM}_{10}$, the primary and secondary standards are identical.
} 


\subsection{Quasi-experimental variation}

Empirical estimates of the true relationship between air quality and housing prices are obscured by a suite of unobserved factors that simultaneously influence both air quality and housing prices. For example, a recently built highway may worsen local air quality but increase local house prices. Such correlations, which we generally expect to bias the estimated price response of air quality toward zero, are at the root of the endogeneity problem that calls for an instrumental variable strategy. My approach treats the 1990 CAAA as a quasi-experiment to address the unobserved factors that affect both housing prices and pollution.

My identification strategy stems from that of Chay and Greenstone (2005) and follows closely that of Bento et al. (2014). Chay and Greenstone exploit the structure of the 1970 CAA to instrument for changes in TSPs at the county level between 1970 and 1980 using county nonattainment status in the mid-1970s. They demonstrate that the attainment designations in 1975 and 1976 are strongly correlated with decadal changes in TSPs and housing prices, but not other county characteristics that may affect home prices (e.g., average income, population), and thus their instrument satisfies the exclusion restriction.

Bento et al. again utilize federal regulation, this time the 1990 CAAA, to instrument for changes in $\mathrm{PM}_{10}$ between 1990 and 2000. In contrast to Chay and Greenstone, they expand the window of mid-decade attainment designations to 1992-97 and, in addition to county attainment status, use individual air quality monitor attainment designations. Due to the fact that an entire county is designated non-attainment when just one monitor exceeds either threshold, optimizing local officials will exclusively target clean-up efforts in the areas around non-attainment monitors (Auffhammer et al. 2009).

Consistent with Bento et al., I use individual air quality monitor readings instead of county averages, however I focus primarily on the monitor attainment designation to identify exogenous changes in air quality. The monitor instrument I construct is the ratio of years that the monitor is out of attainment to the number of years for which there is a record in the years between housing observations. I opt for a ratio instrument over binary to better model heterogeneity in regulation strength. Areas with persistent air quality violations like southern California are likely to have larger reductions in $\mathrm{PM}_{10}$ than areas that infrequently violated the standards. This construction is clarified in Section 2.3. 
For my monitor non-attainment instrument to be valid, it must be correlated with $\mathrm{PM}_{10}$ changes and only affect housing prices through its impact on air quality. First, I examine the time series of $\mathrm{PM}_{10}$ with respect to attainment designation. Figure 1 shows $\mathrm{PM}_{10}$ trends for the years 1989-2001 for three mutually exclusive groups: 1) monitors that exceeded the standards at some point during 1989-2001, 2) monitors in counties that were designated non-attainment at some point during 1989-2001, and 3) monitors never designated non-attainment nor located in a nonattainment county. Figure 1 shows that $\mathrm{PM}_{10}$ levels fell for all three types of monitors, and concentrations converged over the 1990s, which is exactly the intent of the NAAQS. The largest reductions in $\mathrm{PM}_{10}$ clearly occurred for non-attainment monitors, which declined by a total of $18.0 \mu \mathrm{g} / \mathrm{m}^{3}$ over the years 1989-2001, 10.1 more than in-attainment monitors in non-attainment counties and 10.5 more than monitors in in-attainment counties. While county non-attainment monitors do experience additional declines in $\mathrm{PM}_{10}$ compared to county in-attainment monitors, the differential is small and the trends are graphically very similar. Additionally, Figure 1 demonstrates that the majority of air quality improvements occurred early in the decade; $80 \%$ of total $\mathrm{PM}_{10}$ reductions observed for non-attainment monitors had occurred by 1992.

My IV approach relies on the assumption that, conditional on other observable housing, neighborhood, and county characteristics, nonattainment status only affects house prices through its impact on local pollution levels. One concern with this assumption is that the CAAA regulation affects the local economy, and thus indirectly affects home prices. In fact, a substantial body of research has shown that air quality regulation has a significant effect deterring new firms (Becker and Henderson 2000), off-shoring production (Hanna 2010), and on employment levels (Kahn and Mansur 2010, Walker 2011). However, these findings focus on the economic decisions and outcomes of polluting firms only, which represent a relatively small portion of the total economic activity of an area.

To get a sense of the impact of regulation on the overall economic robustness of an area, I analyzed the effect of individual monitor exceedences, as well as the EPA county level attainment designation, on annual measures of county average income, population, and total employment. The results, detailed in the Online Appendix, show that both monitor and county non-attainment measures have an insignificant effect on the three economic measures considered, which is consistent with the ambiguous total impact of non-attainment status found 
by Kahn and Mansur (2010) (see their Table 5). While this analysis is limited, it gives no reason to think that the IV exclusion restriction is violated.

\subsection{Empirical framework}

In this section, I outline the econometric approach I use to estimate the house price response to air quality changes and how households may adjust their location preferences in response to the air quality changes. Because the non-attainment instrument predicts changes in air quality, I use a first difference specification. In order to examine how the price response and sorting behavior may change over time, I construct multiple datasets with differing lags between observations. Since the AHS is sampled every two years, there are five total datasets with lags equal to two, four, six, eight, and ten years. The first and second stage equations of the first difference IV analysis are

$$
\Delta P M_{i j t}=\gamma N_{j t}+\left(\Delta \boldsymbol{X}_{i j t}\right) \boldsymbol{\delta}+\Delta v_{i j t}
$$

and

$$
\Delta p_{i j t}=\theta\left(\Delta \widehat{P M}_{i j t}\right)+\left(\Delta \boldsymbol{X}_{i j t}\right) \boldsymbol{\beta}+\Delta \varepsilon_{i j t}
$$

where $p_{i j t}$ is the natural log of price (either house value or annual rent) of housing unit $i$ matched to air quality monitor $j$ in time period $t, P M_{i j t}$ is the concentration of $\mathrm{PM}_{10}$ for monitor $j$ in time period $t$, and $\boldsymbol{X}_{i j t}$ is a vector of unit and location covariates. The instrument in Equation (1), $N_{j t}$, is based on monitor non-attainment designation. If in Equations (1) and (2), the first difference is taken between years $t_{1}$ and $t_{2}$, then the monitor instrument equals the ratio of non-attainment years to the total number of years of observation during the years $\left[t_{1}+1, t_{2}\right] .^{9} \theta$ is the coefficient of interest and measures the change in log of house price due to a one-unit change in $\mathrm{PM}_{10}$. Implicit in the first difference model is a unit specific fixed effect that absorbs time invariant characteristics of areas that might be correlated with house prices and air quality, such as climate and topographical features, proximity to open space, and transportation infrastructure.

A potentially more intuitive approach to modeling the dynamics of price responses would be regressing changes on housing prices on concurrent changes in pollution and lagged changes in pollution. This specification is less preferred because it necessitates two first stages (or more if

\footnotetext{
${ }^{9}$ If a monitor exceeds the standards in year $t$, then that monitor would be designated non-attainment in year $t+1$. Exceeding the standard in year $t_{1}-1$ could reduce pollution in year $t_{1}$ as well as year $t_{2}$, and thus the effect of nonattainment status in year $t_{1}$ on changes in pollution between $t_{1}$ and $t_{2}$ is ambiguous. For this reason, the range of non-attainment years entering the instrument is $\left[t_{1}+1, t_{2}\right]$.
} 
more than one lag is included) making the local average treatment effect difficult to interpret. However, for completeness, I present estimates from this dynamic specification in Section 4.1. ${ }^{10}$

To explore preference-based sorting in response to changes in air quality, I estimate a variant of the IV first difference model above, except the second stage dependent variable can be a range of variables measuring turnover and changes in demographic characteristics of occupants. ${ }^{11}$ The second stage equation becomes

$$
y_{i j t}=\theta\left(\Delta \widehat{P M}_{i j t}\right)+\left(\Delta \boldsymbol{X}_{i j t}\right) \boldsymbol{\beta}+\Delta \varepsilon_{i j t}
$$

First, I define $y_{i j t}$ to be binary and equal to one if unit $i$ has turned over during the interval ending at $t$ and zero otherwise. In this case, Equation (3) is estimated using a logistic model. Second, I estimate models of sorting on observable characteristics that may be correlated with preferences for air quality: household head over the age of 65, the presence of children under 18, household head is either Black or Hispanic, educational attainment of the household head, and household income. For all characteristics except household income, $y_{i j t}$ is binary and equals one if the demographic characteristic of choice has "increased" (i.e., the household head of the prior occupants was under 65 and the household head of the new occupants is over 65) and equals zero if the demographic characteristic of choice has "decreased". ${ }^{12}$ All unit-intervals that either do not experience turnover or do not have a change in the given demographic group are excluded. This restriction allows me to estimate (3) for this class of sorting models using a logistic model. For household income, $y_{i j t}$ equals the differenced log household income of the entering household from the exiting household, and the sample is still restricted to those units that turnover. Since $y_{i j t}$ is continuous in this case, Equation (3) is estimated using two stage least squares.

\section{DATA}

This section discusses the source and relevant features of the air quality data, regulatory data, housing data (including how local house price trends are managed), neighborhood data, and

\footnotetext{
${ }^{10}$ Another approach would be a Regression Discontinuity research design, similar to Chay and Greenstone (2005). Unfortunately, there are too few non-attainment observations to get the needed density around the cutoff to implement this design.

${ }^{11}$ Theory suggests that sorting will occur when an amenity changes, either for better or for worse, which could lead to an asymmetric effect for improvements versus declines in air quality. Fortunately, the CAAA only induced PM 10 levels to decline, and thus a simple linear specification is sufficient to estimate sorting.

12 The dependent variable for the educational attainment specification equals one if educational attainment has increased with the new occupants (i.e., a high school dropout moves out and either a high school graduate or university graduate moves in) and zero if educational attainment has declined.
} 
county economic activity data, as well as additional details on how the air quality and housing data were matched. The Data Appendix provides a complete listing of all variables used in the regression analysis.

\subsection{Air quality data}

Individual air quality monitor records were obtained from the Air Quality Standards (AQS) database (EPA 2009). Monitors are placed throughout the United States, but are primarily located in urban areas. For each monitor, the database includes the annual mean $\mathrm{PM}_{10}$ concentration, the number of days the $\mathrm{PM}_{10}$ concentration was above the 24-hour threshold, the geospatial coordinates of the monitor, and several reliability measures. For the purposes of my analysis, I restrict monitor-year observations to those that are sufficiently reliable. ${ }^{13}$ For the key measure of air quality, I use the annual mean $\mathrm{PM}_{10}$ concentration.

\subsection{Attainment status}

I construct an attainment status for each monitor-year directly from the AQS data using the same threshold rules as the EPA's county designation. If in a given year a monitor's annual $\mathrm{PM}_{10}$ concentration is greater than $50 \mu \mathrm{g} / \mathrm{m}^{3}$ or its 24 hour concentration exceeds $150 \mu \mathrm{g} / \mathrm{m}^{3}$ for two days or more, then that monitor is designated non-attainment in the following year. Monitor attainment status serves as the main instrument in the IV model.

The western region of the United States contains most of the monitor-year exceedences about $80 \%$ with California making up half. While the price response and sorting models I present are national in scope, California and the West are driving the results.

\footnotetext{
${ }^{13}$ Title 40 Part 58.12 and Title 40 Part 50 Appendix K of the Code of Federal Regulations (CFR) prescribe the monitoring frequencies for $\mathrm{PM}_{10}$ monitors, as well as the criteria for establishing whether a monitor is "representative" and therefore should be included in the analysis. In the AQS data, a criteria flag is set based on data completeness criteria so that if it is set to "Y", then the assumption can be made that the data represent the sampling period of the year. These summary criteria are based on $75 \%$ or greater data capture and data reported for all four calendar quarters in each year. Additionally, I exclude monitor-year observations that are affected by "extreme natural events" beyond human influence. These choices are made to reflect the EPA's designation decisions. When including unreliable monitors in the analysis, the price response patterns are similar but coefficients are attenuated.
} 


\subsection{Housing unit and occupant characteristics}

Housing data for the years 1989-2001 were obtained from the restricted access American Housing Survey National Sample (AHS). The AHS is a panel of housing units that are surveyed every two years, usually between August and November. The AHS collects information about self-reported house value (if owner occupied), rent (if renter occupied), dwelling characteristics (e.g., number of bedrooms, number of bathrooms, whether the unit is rent controlled), occupant characteristics (e.g., race, education, income), and when the current occupants moved in. ${ }^{14} 15$ Importantly, the AHS follows units, not occupants, yielding a high frequency panel of prices.

Unlike the public use version, the restricted access AHS records the census tract where each unit is located. Using GIS, I determined the distance between each tract's geographic center, or centroid, and surrounding air quality monitors. I was then able to match housing units to air quality monitors on the basis of least distance.

To build the datasets used to estimate Equations (1) and (2), I create datasets with two, four, six, eight, and ten years between observations. For example, if a housing unit was surveyed in 1989, 1991, 1993, and 1995, this unit would enter the two-year difference panel with years 1989-1991, 1991-1993, and 1993-1995, the four-year difference panel with years 1989-1993, and the six-year panel with years 1989-1995. The differenced intervals are non-overlapping and priority is given to earlier intervals, as most of the $\mathrm{PM}_{10}$ reductions occurred early in the decade. In the example just given, only one of 1989-1993 and 1991-1995 can be included in the fouryear panel due to the overlap, and 1989-1993 is chosen because it occurs earlier in the decade.

In a similar manner as done with the units, I construct monitor-interval pairs that are then matched with the unit-interval pairs on the basis of least distance. As units get further away from monitors, more measurement error is introduced into the key air quality variable. I exclude all matches greater than three miles in distance to balance measurement error with sample size concerns. This method of matching monitor and unit-intervals ensures that units are matched to the same air quality monitors at the beginning and end of an interval, while still allowing the

\footnotetext{
${ }^{14}$ Kiel and Zabel (1999) examine bias stemming from self-reported prices and find that self-reported values tend to be inflated over market prices, but consistently so. Thus, as long as self-reported values are being compared to other self-reported values, the bias should not affect results.

${ }^{15}$ In addition to the sample restrictions based on distance to a monitor, I exclude unit-year observations when prices are interpolated/“hot decked” or error coded. Further, prices are edited if they are obviously miscoded by omission or insertion of a digit. For instance, if a unit's price sequence is $\$ 100,000, \$ 10,000, \$ 100,000$, then the middle price would be changed to $\$ 100,000$ as it appears a zero was omitted. After editing prices, I exclude units whose prices change by a factor of four in a two-year interval.
} 
monitor-unit match to change across intervals. This strategy balances the competing goals of minimizing measurement error and maximizing sample size. ${ }^{16}$ I chose not to interpolate $\mathrm{PM}_{10}$ values between monitors, so that the attainment designation can be clearly assigned at the monitor level.

\subsubsection{Summary statistics}

The first two columns of Table 1 provide sample means for included housing units and their occupants for owners and renters separately. ${ }^{17}$ A major theme of this paper is disparities between the owner and renter market. Column 3 of Table 1 compares owners to renters for the included sample and shows that the units themselves as well as the occupants differ dramatically between the two groups. Owner-occupied units are on average nearly 1000 square feet larger, have 1.2 more bedrooms, have 0.5 more bathrooms, and are 30 percentage points more likely to have a dishwasher and 20 percentage points more likely to have an air conditioner than renteroccupied units. Owner households make on average \$17,750 more in income and are 20 percentage points less likely to be a minority than renter households. One particularly important difference for the research at hand is the turnover rate, where renter units were 32 percentage points more likely (40\% compared to 8\%) to turn over between 1987 and 1989. Intuitively, the fluidity of the renter market may enable rental prices to respond faster to changes in amenities than owner prices, but this is of course not the only difference between the two markets. These substantial differences are especially remarkable given that included units are located primarily in urban areas and that, in general, much of the difference between the owner and renter market stems from the fact that most rental units are in the urban core and owner-occupied units are disproportionately in the suburbs. These differences reinforce the motivation for estimating all models separately for owner-occupied and renter-occupied units.

Finally, consider the relationship between attainment designation and housing unit and occupant characteristics. Columns 4 and 5 of Table 1 examine the pre-treatment conditions of the housing units, comparing unit and occupant characteristics in 1989 for housing units matched to non-attainment monitors versus in-attainment monitors, again comparing owners and renters separately. Owner-occupied units in monitor non-attainment areas are worth less, are smaller,

\footnotetext{
${ }^{16}$ Requiring a unit to only match with one monitor reduces sample size by $22-29 \%$ depending on the interval. Price response patterns are similar with this restriction imposed.

${ }^{17}$ Sample means for excluded units and non-attainment and in-attainment units are given in the Online Appendix.
} 
and have fewer appliances. The differences in housing values are suggestive of a compensating differential for air quality differences, but could also be mostly or entirely due to differences in housing stock or other locational amenities across different areas that happen to be correlated with air quality levels. Rental rates in monitor non-attainment areas are actually higher, which underscores the difficulty with cross sectional estimation. While many demographic variables are not significantly different between the groups, non-attainment areas have fewer high school

graduates, but more college graduates. One of the most important pre-treatment characteristics to consider is prior appreciation of housing prices because an existing price trend could bias valuation estimates. Table 1 shows no statistically significant difference in prior appreciation; a robustness check in the Online Appendix confirms inclusion of past price changes does not affect results. In addition, there is not a statistically significant difference in either changes in household income or the rate of turnover between 1987 and 1989. While the groups are not perfectly balanced pre-treatment, the statistics offer no reason to be concerned about confounding effects of the identification strategy.

\subsection{Local housing market trends}

Because the scope of this study is national and thus compares appreciation rates across many cities and regions, it is necessary to control for local housing market trends. If regional house price trends are correlated with patterns of air quality improvements, the valuation estimates could reflect those trends instead of responses to air quality changes. I institute a novel method that controls for local housing market trends by using external data. Freddie Mac publishes the Conventional Mortgage Home Price Index (CMHPI), which gives quarterly estimates of home price levels (Freddie Mac 2010). Freddie Mac offers MSA specific indices for 11 large MSAs (Boston, Chicago, Dallas-Ft. Worth, Detroit, Los Angeles, Miami, New York, Philadelphia, San Francisco, Seattle, and Washington DC), as well as state specific indices for every state. If a housing unit is located within one of the 11 MSAs, then it is matched to that index, otherwise it is matched to the state index. Using each of these MSA/state-specific indices, all housing prices were brought to 2001 levels using the third quarter index (to match the 
sampling schedule of the AHS). ${ }^{18}$ Given the adjustments made to house prices using the CMHPI, the dependent variable in the valuation regressions is, in essence, appreciation relative to the local housing market trend. Thus, while the scope of the study is national, I am able to compare housing price changes from one part of the country to another because all price changes are relative to a smaller market. Another approach would be to include state-by-year or MSA-byyear fixed effects in the regression model to control for unobservable trends and shocks that may bias the estimated relationship. However, given the sparseness of AHS data and spatial concentration of non-attainment air quality monitors, this strategy captures too much variation to still identify the price-pollution gradient; CMHPI de-trending is used as a similar second best option. One limitation of the CMHPI is that it is an index comprised of only owner-occupied prices. In Section 4.2, I investigate how using a price index derived exclusively from rental data affects the estimated rent response.

Much like housing prices, there are regional trends in turnover and demographics that must be taken into account in order to accurately measure preference-based sorting at a national scale. Unfortunately, no analogous CMHPI exists for demographic changes. As a second best, I include changes in turnover and demographic characteristics at the MSA level (aggregated from decennial census data) as covariates in the estimation of (3). ${ }^{19}$ With this strategy, the locational choice of, for example, households over 65 in response to changes in $\mathrm{PM}_{10}$ is conditional on the MSA level changes in the over 65 population.

\subsection{Neighborhood characteristics}

The socioeconomic characteristics of neighbors are, without question, an important piece of a housing unit's value or rent. While the AHS offers many benefits, the observations are nowhere near spatially dense enough to measure important neighborhood variables. To alleviate this restriction, I use the census tract identifier in the AHS to include tract level decennial census

\footnotetext{
${ }^{18}$ For specificity, if $y_{\text {imt }}$ is the house price of unit $i$ in MSA $m$ in year $t$ in current dollars, then the CMHPI adjusted house price is $\hat{y}_{i m t}=y_{i m t} / c m h p i_{m t}$ where $c m h p i_{m t}$ is the price index for MSA $m$ in year $t$, with $c m h p i_{m 2001}$ normalized to 1 for all $m$.

${ }^{19}$ Effective MSAs are constructed by grouping units in the same MSA, and then grouping units not located in a MSA by state.
} 
data from GeoLytics Neighborhood Change Database. ${ }^{20}$ Of course, these data are only available in 1990 and 2000, and I assume a linear trend to impute values for all years 1989-2001.

\subsection{County economic characteristics}

From the Bureau of Economic Analysis (BEA), I include annual average county income, and I include employment data from the County Business Patterns (CBP) database. CBP gives yearly employment counts broken down by Standard Industrial Classification/North American Industry Classification System codes for each county. I aggregate the number of jobs into five major categories that are intended to be most relevant to air quality: construction, manufacturing, mining, agriculture/forestry, and a catch all for the remaining codes.

\section{Price Response Results}

Tables 2 and 3 present the results for the IV first difference model, presented in Equations (1) and (2), for interval lengths of two, four, six, eight, and ten years for owneroccupied and renter-occupied units, respectively. ${ }^{21}$ Consistent with expectations, the monitor non-attainment instrument performs well in predicting drops in particulate matter. Just focusing on Table 2, the coefficient on monitor non-attainment is -5.75 for the two-year lag, then increases to -12.10 for the four-year lag and -19.21 for the six-year lag, and then remains roughly at that level: -22.03 and -16.22 for the eight- and ten-year lags, respectively. ${ }^{22}$ F-statistics range from 21.36 to 75.61, suggesting a strong instrument and, indeed, that regulation has a strong effect on air quality. The first stages are approximately the same for owners and renters, but differ slightly due to different values for covariates and a slight difference in the set of monitors matched to the sample. The first stage estimates parallel the pattern observed in Figure 1 that air

\footnotetext{
${ }^{20}$ The available years of AHS data only give census tract codes for 1980 and 1990, with 1990 codes only appearing for observations in 1997 and after. I obtained the historical tract boundaries from NHGIS (Minnesota Population Center 2004). Using GIS, I overlaid historical boundary files with the 2000 boundaries to determine weights such that the neighborhood variables from Geolytics could be reconstructed for 1980 or 1990 boundaries.

${ }^{21}$ For the sake of comparison, the Online Appendix additionally reports results from first differenced models (without instrumenting). The first difference results show smaller and statistically insignificant magnitudes of price response, reinforcing the importance of the IV strategy.

${ }^{22}$ The two-year interval coefficient on the instrument is similar in magnitude to other decadal studies: Chay and Greenstone (2005) estimate non-attainment status decreased $\mathrm{PM}_{10} 5.2 \mu \mathrm{g} / \mathrm{m}^{3}$ (after translating TSP to $\mathrm{PM}_{10}$ ) and Grainger (2012) estimates non-attainment status decreased $\mathrm{PM}_{10} 4.2 \mu \mathrm{g} / \mathrm{m}^{3}$. This suggests that households are able to discern and value changes of the magnitude $4-6 \mu \mathrm{g} / \mathrm{m}^{3}$ over a decade. The prior literature does not give any indication of whether that magnitude of change can be detected and valued in a 2-4 year time span, but my results suggest yes. The longer intervals have larger coefficients on the instrument than the other decadal studies due to the focus on individual monitors instead of county averages.
} 
quality improved quickly after the onset of the 1990 CAAA and then stayed relatively constant across areas. The results also suggest that identification of the second stage parameters is not off of regression to the mean, as the impact of non-attainment grows with interval length.

Turning to the second stage, Table 2 convincingly shows that declines in $\mathrm{PM}_{10}$ cause owner-occupied housing prices to appreciate. Coefficient estimates range from -0.0059 to -0.0139, with all estimates statistically significant at the 5\% level or higher. Corresponding elasticities range from -0.23 to -0.63 , with the six-year and ten-year interval being the minimum and maximum, respectively. The variance in estimates across intervals is likely due to the volatility of prices in the owner market, and the "true” marginal capitalization rate probably lies in the middle of the range. It is worthwhile to compare these estimates with others. The ten-year interval estimate of an elasticity of -0.63 is best to compare with estimates derived from Decennial Census data, which has been the most common source of data in the literature. Chay and Greenstone (2005) report elasticity of -0.28; for Bayer et al. (2009), the estimate is -0.63; Grainger (2012) finds -0.51; and Bento et al. (2014) report $-0.60 .^{23}$ My estimates are consistent with others, especially those using 1990-2000 data.

Switching to the second stage renter results, Table 3 demonstrates that, like owneroccupied units, rental prices increase with increases in air quality. For intervals two and four, coefficient estimates are small (-0.0021 and -0.0025) and statistically insignificant, but then sharply jump to a statistically significant -0.0076 for the six-year interval and continue all the way to -0.0203 at a lag of ten years. At a lag of two years, the elasticity is -0.06 . At a lag of ten years, the elasticity is over ten times larger at -0.87 . The ten year interval estimates contrast with other estimates using Decennial Census data; both Grainger (2012) and Bento et al. (2014) find estimated renter elasticities to be about a third of what it is for owners. The discrepancy could be a function of their use of median values or aggregation bias.

Comparing the results for owners and renters, markedly different capitalization patterns emerge. For owners, there is no pattern of increasing or decreasing capitalization coefficients, though there is variance in the estimates across intervals. Thus, the results suggest that owneroccupied units capitalize changes in air quality quickly. In contrast, coefficients for renters

\footnotetext{
${ }^{23}$ The Chay and Greenstone estimates are for TSP and increased by a factor 1.82 to be comparable to $\mathrm{PM}_{10}$. The estimates drawn from Bayer et al. do not account for migration costs; elasticity increases when doing so. Kuminoff and Pope (2014) caution against interpreting capitalization as a measure of marginal willingness to pay, but as an additional comparison, my estimates yield MWTP in the range of $\$ 83$ to $\$ 212$, which is consistent with past research as well.
} 
steadily grow in magnitude and significance as the length of the interval grows. The 10-year coefficient is statistically different than the two- and four-year estimates with p-values of 0.08 and 0.075, respectively. For owners, the corresponding p-values are 0.33 and 0.62. Comparing coefficients between owners and renters, the four-year estimates are statistically different with a p-value of 0.04; the other intervals are not statistically different at conventional levels. Despite being initially low, elasticities for rental price responses reached parity with owners by the ten year interval. Given the sum of evidence, I conclude that rental prices are slower to respond to air quality changes than owner prices. ${ }^{24}$

The comparison between owner and renter results leads to counterintuitive insights. First, conventional wisdom and some research (e.g., Banzhaf and Farooque 2013, Winters 2012) suggest that the renter market is better suited for valuation studies than the owner market because the high turnover rates and low financial costs of moving should allow prices to adjust quickly. However, the results here indicate that the fluidity of a market does not correspond to the speed of price response. It could be that households looking to own versus rent are more attentive to amenity levels. ${ }^{25}$ This is untestable in the current data, but recent rounds of the AHS contain questions on factors driving neighborhood choice. Of recent movers, the proportion of owners that chose their neighborhood based on looks or design was two-thirds larger than the same proportion for renters; in contrast, the proportion of renters that chose their neighborhood based on convenience to job or public transit was twice as large as the same proportion for owners (US Census Bureau 2013).

Second, the results suggest that the rental market and owner market are not as closely linked as conventional wisdom holds. The valuation sharply and immediately diverges, but there is no evidence that this divergence is arbitraged either through financial instruments or people delaying home purchase to rent. However, the maximum disparity in annual costs resulting from air quality improvements, which is estimated to be at a lag of four years, is only $\$ 602$, where the average increase in annual costs of living in a treated area are \$652 for homeowners and \$50 for

\footnotetext{
${ }^{24}$ Due to the near exact relationship between air quality changes for renters and owners, the delay in price response for renters is not merely mechanically caused by attenuation bias in short intervals stemming from measurement error in air quality readings.

${ }^{25}$ An additional facet of the possibility of differing perceptions is that owner households may be more forwardlooking and more likely to form expectations about future air quality changes and be willing to pay based on those expectations. If this is the case, the short interval, owner valuation may reflect both concurrent changes in air quality and expected future changes, and this may explain some of the differing patterns of price response. Given the IV framework it is infeasible to test for expectations.
} 
renters. ${ }^{26}$ While not insubstantial, this $\$ 602$ difference is unlikely to be enough to induce arbitrage given the vast disparities among units and occupants between the two markets.

The suite of results for owners and renters is robust to using a two- or four-mile cutoff for monitor matches, controlling for sample selection by using only units that have at least 10 years of complete data, and controlling for pre-treatment price trends, as detailed in the Online Appendix.

\subsection{Dynamic Price Response Model}

As a robustness check, Table 4 presents results from a model that regresses change in housing prices on concurrent changes in $\mathrm{PM}_{10}$ and lagged changes in $\mathrm{PM}_{10}$. With this model, two first stage regressions are needed and the monitor non-attainment instrument for the current interval and lagged interval are both used as instruments. I estimate this model only for the twoyear interval data because the other models have weak identification for the current change in $\mathrm{PM}_{10}$ due to the vast majority of non-attainment designations occurring early in the decade.

The results for owners, shown in the first column of Table 4, show that concurrent changes in $\mathrm{PM}_{10}$ are capitalized at a statistically significant rate of -0.0138 , which is at the upper end of the estimates in Table 2. In contrast, lagged changes in $\mathrm{PM}_{10}$ have no capitalization effect on owner values. Turning to the renter results in the second column, the price response for concurrent changes in $\mathrm{PM}_{10}$ is statistically insignificant and even the perverse sign. However, the coefficient on lagged changes in $\mathrm{PM}_{10}$ is -0.0118 , which is also on the larger side of estimates in Table 3, though also statistically insignificant. Further, the coefficients on concurrent changes for owners and renters are statistically significantly different with a p-value of 0.04 . These results bolster those seen in Tables 2 and 3 that suggest that owner prices respond immediately to changes in amenities while renter prices lag behind amenity changes.

\subsection{Testing hypotheses for delayed rental price response}

Table 5 offers a series of results from models that test three hypotheses for the cause of the delay in rental price response: 1) rental market rigidities, 2) disparities between rental and owner units in terms of geography and occupant and unit characteristics, and 3) using an

\footnotetext{
${ }^{26}$ The annual costs due to PM10 improvements are calculated by multiplying price response coefficients by an annualized cost of housing and by the first stage coefficient and by the average instrument value for treated areas.
} 
inappropriate price index. Sample sizes and first stage results are omitted due to disclosure restrictions. ${ }^{27}$ In each case the first stage is similar to that of Table 3.

Panels A and B of Table 5 test whether price rigidities in the rental market could be causing the delay in price adjustment. The concern is that landlords tend to keep rental prices nominally unchanged from year to year when tenants renew a lease (Genesove 2003). Further, tenants in rent-controlled apartments tend to move less, and typically landlords can only modestly (if at all) adjust prices unless there is turnover. ${ }^{28}$ Thus, only when tenants leave do landlords raise rents to market levels that would reflect a change in amenities. To address this possibility, the Panel A specification excludes all units under rent control and Panel B includes only unit-intervals with turnover. In Panel A, the two- and four-year coefficients are double compared to those seen in Table 3, and the four-year coefficient is significant at the $5 \%$ level. However, the ten-year estimate is five times larger than the two-year estimate and four-year price response estimate is still statistically different than the coefficient for owners (from Table 2). This suggests that rent control does impede some short term price response, but a lag in full price response still persists. The results of Panel B show a remarkably similar pattern of delayed price response to Table 3, suggesting that delayed price adjustment is common to all rental units, regardless of occupant tenure.

Panels C, D, and E of Table 5 test whether disparities between rental and owner units and occupants could be causing the delay in price response. Panel C ensures geographic overlap with owner units by limiting the sample to air quality monitors that match to both owner- and renteroccupied units. If the spatial distribution is uneven and different areas experience different appreciation rates, then comparisons between owners and renters could be flawed. The results support the finding of delayed price response for renters. Panels D and E weight renter observations by the probability that they are owned. Table 1 demonstrated the significant differences between the characteristics of renter- and owner-occupied units and their occupants. If, for example, the types of units that wealthier people like to occupy appreciate faster than average, then this alone could explain the disparities in price response patterns. For both of these

\footnotetext{
${ }^{27}$ As the sample changes with each cut of the data, the sample sizes and first stage results are withheld to minimize disclosure risk. This does not indicate small sample sizes; the Census Bureau requires both the desired cut and the omitted observations (or "shadow sample") to pass disclosure tests. By not disclosing first stage results and sample sizes, I circumvent the disclosure test and can report results from more cuts of the data.

${ }^{28}$ This is especially important since rent control is practiced in Los Angeles (Los Angeles Housing Department 2012), which comprises a disproportionate share of the treatment group.
} 
models, a logit regression is estimated with the dependent variable equal to one if the unit is owner-occupied and zero if renter-occupied, then the estimated probabilities of a unit being owned are used to weight the renter observations. Panel D uses occupant characteristics (income, head is black or Hispanic, head is college graduate) to predict ownership, and Panel E uses both occupant and unit characteristics (number of bedrooms, number of bathrooms, central AC). The results for Panel D closely match those of Table 3 in terms of magnitude and significance. Panel E shows the same pattern of delayed price response, but the standard errors have grown substantially.

Panel F of Table 5 tests whether using the CMHPI, a price index based on owneroccupied sales, to de-trend rental rates could be causing the delay in price response. As an alternative, I create a similar index for each MSA using only AHS rental observations, but using the entire sample of the AHS, not just those that match to air quality monitors. ${ }^{29}$ There is a correlation of 0.86 between these two indices, and this is reflected in the results that are qualitatively identical to those in Table 3.

This section has examined three hypotheses regarding the delay in rental price response, but none have been able to explain the result. Given this, it seems likely that the disparities in price response patterns are attributable to differences in attentiveness about amenity levels. Because owners have a longer expected tenure and a greater financial stake in their location, they may be more likely to perceive changes in amenities, especially one like air quality that is imperfectly observed.

\section{SORTING RESUlts}

The delayed but sharply rising price response observed in the rental market offers an excellent opportunity to examine the relationship between valuation and preference-based sorting. ${ }^{30}$ The price response results suggest that something fundamentally changes going from the two- and four-year interval to the six-, eight-, and ten-year intervals. If there is a relationship between sorting and valuation, a similar shift in the turnover rate or demographics should occur at the six-year interval.

\footnotetext{
${ }^{29}$ I also pursued using the REIS Inc. rent index, but it was prohibitively expensive for the timeline and geographic scope of my data.

${ }^{30}$ The corresponding owner-occupied sorting analysis is presented in the Online Appendix. Given the relative infrequency of moves among owner-occupiers, the data is inadequate to draw conclusions.
} 
Table 6 presents the results from estimates of Equation (3), giving the second stage coefficients on $\mathrm{PM}_{10}$, as well as the implied marginal effects. Again, sample sizes and first stage results are omitted due to disclosure restrictions. Panel A examines whether changes in $\mathrm{PM}_{10}$ cause turnover to increase, and the model is estimated on the full sample appearing in Table 3. A negative coefficient implies that a reduction in $\mathrm{PM}_{10}$ increases the rate of turnover, which would be suggestive of preference-based sorting (with preferences potentially uncorrelated with observable characteristics). The estimated coefficients are positive and insignificant for intervals two and four. However, for intervals six and eight, the coefficient becomes negative and statistically significant. Further, the jump in the probability of turnover is economically significant; the total estimated increase in probability from four to six years given the total reductions in $\mathrm{PM}_{10}$ is $10.1 \%$. For interval ten, the coefficient is positive and insignificant again.

Panels B through F of Table 6 show the results of the sorting on observables analysis giving the estimates of the effects of $\mathrm{PM}_{10}$ on demographic changes. A negative coefficient implies that a reduction in $\mathrm{PM}_{10}$ increases the propensity of the given demographic group to move into rather than move out of that neighborhood. The results of Panel B suggest that improvements in $\mathrm{PM}_{10}$ consistently increase the likelihood of households with children under 18 years of age of moving into an area. For intervals two and four the estimates are small and insignificant, but for intervals six, eight, and ten the estimates are larger and statistically significant. The six-year interval estimate implies a total increase in likelihood of $18.2 \%$. Panel C suggests that older residents are more likely to be moving out of, rather than into, a neighborhood in response to a decline in $\mathrm{PM}_{10}$. While initially surprising given that the elderly are vulnerable to adverse health effects from poor air quality, this result is likely a product of small sample size - only $12 \%$ of the renter population is over 65 and they tend to be less mobile than others - leading to weak instruments and inflated second stage values, and thus little confidence is placed on these results. The ten year interval estimate is omitted because the first stage F-stat is less than 1.0. The results of Panel D and E suggest that the minority status and educational attainment, respectively, of a household are both unresponsive to changes in air quality, as coefficients flip signs multiple times and are mostly insignificant. ${ }^{31}$ Lastly, the household income results in Panel F suggest that the income level of new residents was lower than old residents for interval two, but flips signs and is insignificant for all other intervals.

\footnotetext{
${ }^{31}$ Examining Black households and Hispanic household separately does not qualitatively affect the results.
} 
The results of the sorting analysis suggest that changes in turnover frequency and the location preferences of households with children are responsive to changes in air quality and correspond to the rental price response patterns. Intuitively, households with children should value improvements in air quality more than households without children due to health concerns. However, we might also think that preferences may be correlated with income and education, but the results show no evidence of this.

The sorting results introduce the possibility that some portion of the price increase is due to preferences for living near households with children or some unobservable trait common to the households that moved into cleaned up areas (the social multiplier logic of Bayer et al. 2007). While I cannot partition direct and indirect price effects, logically it seems likely that most is direct given that income, race and education levels (which are the key drivers in Bayer et al.) do not change on average between old and new occupants in cleaned up areas.

\section{Discussion AND CONCLUSION}

This paper uses rich housing market data and spatially disaggregated air quality data to examine changing housing prices and changing locational preferences in response to air quality changes brought on by differential regulatory pressure from the CAAA. This is the first paper to study the dynamic path of price adjustment in response to air quality changes and the first paper to examine the dynamics of price response to any changing amenity for owners and renters separately. The results suggest a disconnect between air quality price response patterns in the owner and renter markets. While owner-occupied houses capitalize changes immediately and the capitalization rate stays fairly constant over time, renter-occupied unit prices are slow to respond but then sharply increase up to the point that the elasticity estimates are on par for both groups. Tests of statistical differences support the ideas that rental price responses increase over time and that short-term price responses are different for owners and renters, though with the later point, the evidence is mixed.

Conventional wisdom and stylized facts suggest several possibilities why the disparities in dynamic price response paths may exist. First, there are significant housing and occupant characteristic differences between owners and renters. If these differences are somehow correlated with perceptions of air quality changes then this could drive different dynamics. Second, the structure of the rental market may be such that it impedes rapid price changes, 
through rent control or just infrequent price changes. Both of these ideas, however, fail to empirically explain the delay in rental price response. A final possibility, which is untestable in the current setting, is that owners may be more attentive of PM levels given their anticipated tenure and financial stake in the property. Supporting evidence of this, though indirect, comes from more recent AHS rounds that indicate owners are more likely to choose a house based on the looks of the neighborhood than renters, whereas renters are more likely to choose a house based on proximity to jobs and public transit (US Census Bureau 2013). The conventional wisdom that the renter market is better suited for valuation studies than the owner market given high turnover rates and low financial moving costs does not bear out in this dynamic setting.

Regardless of why prices lag air quality changes in the rental market, it offers an opportunity to examine the relationship between price response and locational sorting. The results of the preference-based sorting analysis suggest that the turnover of rental units and the propensity for households with children to move into a unit both increase in recently cleaned up neighborhoods. This finding suggests heterogeneous preferences for air quality among renters, at least some of which is correlated with households with children. Importantly, the timing of the sorting coincides with price increases, both at a six year lag. Prior literature that has examined the links between price response and preference-based sorting has typically taken a cross sectional, equilibrium approach. This paper's ability to observe the true dynamics offers additional and unique evidence bolstering the long-standing intuition of Tiebout's "vote with your feet” ideas.

Given that we do see an increase in the turnover rate, there may be a concern that renters suffer a welfare loss when air quality improves (e.g., Starrett 1981, Sieg et al. 2004, Grainger 2012). The fear is that when amenities improve, all of the new value goes to the non-resident owner, who can then charge higher rent leaving the tenants no better off - and potentially worse off if the renters cannot afford the new rent and must relocate into an area with worse air quality. While the sorting results in this paper suggest there is an increase in turnover, the results also show that the new occupants are no wealthier or better educated or whiter than the previous tenants. A related environmental justice concern is raised by Banzhaf and Walsh (2013), who argue that improvements in public goods will lead to increases in racial segregation. The results presented here fail to find support for that concern. A full welfare analysis is beyond the scope of 
this paper, but at a minimum the results suggest that air quality improvements had an ambiguous welfare effect on renters.

While the results as a whole inform policy by offering more evidence that households value clean air, more importantly the results inform methods of policy evaluation. Price changes in the housing market are frequently used to valuate preferences, measure benefits, and assess damages. The owner results, suggesting immediate and full capitalization of an imperfectly observed amenity, are a testament of the efficacy of the hedonic approach. However, the renter results suggest that if the timeframe of analysis is insufficient, then the estimated price response could be severely underestimated. Specifically, in the case of the valuation of the significant air quality improvements in the 1990s, if the time frame of study was too short, then the valuation estimates could be as little as one tenth of the true value. Future work should continue to explore disparate responses to amenity changes in the owner and rental market and seek to understand perceptions and belief formation among these two groups.

\section{REFERENCES}

Auffhammer, Maximilian, Antonio M. Bento, and Scott Lowe. (2009). "Measuring the effects of the Clean Air Act Amendments on ambient PM10 concentrations: The critical importance of a spatially disaggregated analysis." Journal of Environmental Economics and Management 58(1): 15-26.

Banzhaf, H. Spencer and Omar Farooque. (2013). "Interjurisdictional housing prices and spatial amenities: Which measures of housing reflect local public goods?" Regional Science and Urban Economics 43(4): 635-648.

Banzhaf, H. Spencer and Randall P. Walsh. (2008). "Do people vote with their feet? An empirical test of Tiebout's mechanism." American Economic Review 98(3): 843-863.

Banzhaf, H. Spencer and Randall P. Walsh. (2013). "Segregation and Tiebout sorting: The link between place-based investments and neighborhood tipping." Journal of Urban Economics 74: 83-98.

Bayer, Patrick, Fernando Ferreira and Robert McMillan. (2007). “A unified framework for measuring preferences for schools and neighborhoods.” Journal of Political Economy 115(4): 588-638. 
Bayer, Patrick, Nathaniel Keohane and Christopher Timmins. (2009). "Migration and hedonic valuation: The case of air quality." Journal of Environmental Economics and Management 58(1): 1-14.

Becker, Randall and J. Vernon Henderson. (2000). "Effects of Air Quality Regulations on Polluting Industries.” Journal of Political Economy, 108(2): 379-421.

Bento, Antonio M., Matthew Freedman, and Corey Lang. (2014). "Who Benefits from Environmental Regulation? Evidence from the Clean Air Act Amendments.” forthcoming, Review of Economics and Statistics.

Blanchard, Olivier J. and Lawrence F. Katz. (1992). "Regional Evolutions". Brookings Papers on Economic Activity. 1: 1-75.

Cameron, Trudy Ann and Ian T. McConnaha. (2006). "Evidence of environmental migration." Land Economics 82(2): 273-290.

Card, David, Alexandre Mas, and Jesse Rothstein. (2008). "Tipping and the dynamics of segregation." Quarterly Journal of Economics 123(1): 177-218.

Case, Bradford, Henry O. Pollakowski, and Susan M. Wachter. (1997). "Frequency of transaction and house price modeling." Journal of Real Estate Finance and Economics 14(12): 173-187.

Case, Bradford and John M. Quigley. (1991). "The dynamics of real-estate prices." Review of Economics and Statistics 73(1): 50-58.

Cellini, Stephanie R., Fernando Ferreira, and Jesse Rothstein. (2010). "The value of school facility investments: Evidence from a dynamic regression discontinuity design." Quarterly Journal of Economics 125(1): 215-261.

Chay, Kenneth Y. and Michael Greenstone. (2005). "Does air quality matter? Evidence from the housing market." Journal of Political Economy 113(2): 376-424.

Daniels, Michael J., Francesca Dominici, Jonathan M. Samet, and Scott L. Zeger. (2000). "Estimating particulate matter-mortality dose-response curves and threshold levels: An analysis of daily time-series for the 20 largest US cities." American Journal of Epidemiology 152(5): 397-406.

Davis, Lucas. (2011). “The effect of power plants on local housing prices and rents.” Review of Economics and Statistics 93(4): 1391-1402.

Dominici, Francesca, Michael J. Daniels, Jonathan M. Samet, and Scott L. Zeger. (2002). "Air pollution and mortality: Estimating regional and national dose-response relationships." Journal of the American Statistical Association 97(457): 100-111. 
Figlio, David N. and Maurice E. Lucas. (2004). "What's in a Grade? School Report Cards and the Housing Market". American Economic Review. 94: 591-604.

Freddie Mac. (2010). "Conventional Mortgage Home Price Index." Last retrieved November 1, 2010 from, www.freddiemac.com/finance/cmhpi/.

Genesove, David. (2003). "The nominal rigidity of apartment rents." Review of Economics and Statistics 85(4): 844-853.

Glaeser, Edward L. and Josheph Gyourko. (2007). “Arbitrage in housing markets.” NBER Working Paper \#13704.

Grainger, Corbett. (2012). “The Distributional Effects of Pollution Regulations: Do Renters Fully Pay for Cleaner Air?” Journal of Public Economics 96(9-10): 840-852.

Greenstone, Michael and Justin Gallagher. (2008). "Does hazardous waste matter? Evidence from the housing market and the superfund program." Quarterly Journal of Economics 123(3): 951-1003.

Hall, Jane, Arthur Winer, Michael Kleinman, Frederick Lurman, Vic Brajer, and Steven Colonme. (1992). "Valuing the health benefits of clean-air." Science 255(5046): 812-817.

Hanna, R. (2010). “U.S. environmental regulation and FDI: Evidence from a panel of U.S. based multinational firms.” American Economic Journal: Applied Economics, 2(3), 158-89.

Imbens, Guido W. and Joshua D. Angrist (1994). "Identification and estimation of local average treatment effects." Econometrica 62(2): 467-475.

Kahn, Matthew E. and Erin T. Mansur. (2010). “How do energy prices, and labor and environmental regulations affect local manufacturing employment dynamics? A regression discontinuity approach.” NBER Working Paper 16538.

Kiel, Katherine A. and Jeffrey E. Zabel. (1999). "The accuracy of owner-provided house values: The 1978-1991 American Housing Survey." Real Estate Economics 27(2): 263-298.

Kuminoff, Nicolai V. and Jaren C. Pope. (2014). "Do 'capitalization effects' for public goods reveal the public's willingness to pay?" International Economic Review, 55(4), 1227-1250.

Los Angeles Housing Department. (2012). "Rent stabilization ordinance information.” Retrieved February 12, 2012, from http://lahd.lacity.org/.

Minnesota Population Center. National Historical Geographic Information System: Pre-release Version 0.1. Minneapolis, MN: University of Minnesota (2004). Available at http://www.nhgis.org 
Pope, Jaren C. (2008). "Buyer information and the hedonic: The impact of a seller disclosure on the implicit price for airport noise." Journal of Urban Economics 63(2): 498-516.

Rosen, Sherwin. (1974). "Hedonic prices and implicit markets - Product differentiation in pure competition." Journal of Political Economy 82(1): 34-55.

Sieg, Holger, V. Kerry Smith, H. Spencer Banzhaf, and Randy Walsh. (2004). "Estimating the general equilibrium benefits of large changes in spatially delineated public goods." International Economic Review 45(4): 1047-1077.

Starrett, David A. (1981). "Land-value capitalization in local public-finance." Journal of Political Economy 89(2): 306-327.

Tiebout, Charles M. (1956). "A pure thoery of local expenditures." Journal of Political Economy 64(5): 416-424.

Unites States Environmental Protection Agency. (2009). "Air Quality Standards Database." Last retrieved September 1, 2009, from www.epa.gov/aqspubl1/.

Unites States Environmental Protection Agency. (2010). "Particulate Matter (PM)." Last retrieved November 1, 2010, from www.epa.gov/.

U.S. Census Bureau,Current Housing Reports, Series H150/11, American Housing Survey for the United States: 2011,U.S. Government Printing Office,Washington, DC, 20401.Printed in 2013.

Walker, W. Reed. (2011). "Environmental regulation and labor reallocation: Evidence from the Clean Air Act." American Economic Review 101(3): 442-447.

Winters, John V. (2012). "Differences in Quality of Life Estimates Using Rents and Home Values." IZA Discussion Paper 6703. 


\section{DATA APPENDIX}

\section{$\underline{\text { List of variables used as covariates in regressions }}$}

Unit Characteristics (from the American Housing Survey)

New roof between beginning and end of interval (1=yes) ${ }^{*}$

Kitchen remodeled between beginning and end of interval (1=yes) ${ }^{*}$

New or remodeled bathroom between beginning and end of interval (1=yes) ${ }^{*}$

Other addition between beginning and end of interval (1=yes) ${ }^{*}$

Rent control at beginning of interval $(1=y e s)^{\dagger}$

Rent control at end of interval (1=yes $)^{\dagger}$

Neighborhood Characteristics (from the Decennial Census)

Population density

Share Black ${ }^{ \pm}$

Share Hispanic ${ }^{ \pm}$

Share over $60^{ \pm}$

Share under $5^{ \pm}$

Share foreign born

Share high school graduate ${ }^{ \pm}$

Share college graduate ${ }^{ \pm}$

Share unemployed

Share below poverty line

Share receiving welfare benefits

Share living in the same residence for 5 years ${ }^{ \pm}$

$\ln$ (median family income) ${ }^{\neq}$

Total housing units

Share of units occupied

Share of occupied units that are owner occupied

County Economic Characteristics (from County Business Patterns and the Bureau of Economic Analysis) $\ln ($ number of jobs in construction +1 )

$\ln ($ number of jobs in manufacturing +1 )

$\ln$ (number of jobs in mining +1 )

$\ln$ (number of jobs in agriculture or forestry +1 )

$\ln ($ number of jobs in all other sectors +1 )

$\ln$ (average county income)

\footnotetext{
* Only available for owner-occupied units.

${ }^{\dagger}$ Only included for renter-occupied specifications.

${ }^{ \pm}$These tract level variables were replaced with MSA averages for the sorting analyses. Additionally, the education variables were replaced with a single variable, average educational attainment, equal to the share of college graduates minus the share of high school dropouts.

${ }^{\neq}$Removed for sorting analysis since county average income is available at higher frequency from BEA.
} 


\section{Figures and Tables}

Figure 1: PM10 concentrations across time by attainment status

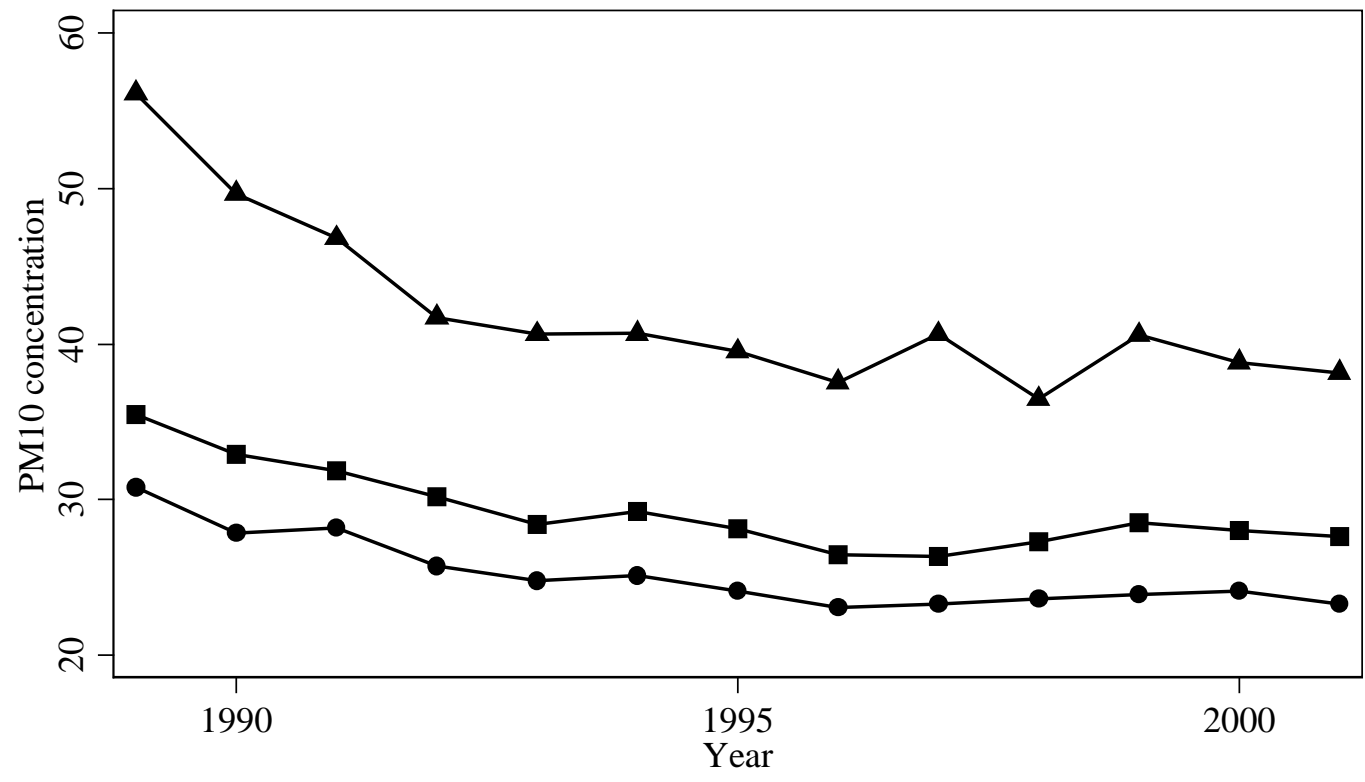

C County in-attainment, Monitor in-attainment

$\longrightarrow$ County non-attainment, Monitor in-attainment

Monitor non-attainment

Notes: Each air quality monitor in the sample is split into attainment categories by the following rule. If a monitor ever exceeds the NAAQS PM10 standards during 1989-2001, then that monitor is put in the 'Monitor non-attainment' group. If a monitor never exceeds the thresholds, but is located within a county

designated non-attainment by the EPA at some point during 1989-2001, then that monitor is put in the 'County non-attainment, Monitor in-attainment' group. All other monitors are put in the 'County in-attainment, Monitor in-attainment' group. 


\begin{tabular}{|c|c|c|c|c|c|}
\hline \multirow[b]{2}{*}{ Variable } & \multicolumn{2}{|c|}{ Sample means } & \multirow[t]{2}{*}{$\begin{array}{l}\text { Difference of } \\
\text { owner and } \\
\text { renter means }\end{array}$} & \multicolumn{2}{|c|}{$\begin{array}{c}\text { Difference of } \\
\text { non-attainment and } \\
\text { in-attainment } \\
\text { means }\end{array}$} \\
\hline & owners & renters & & owners & renters \\
\hline & $(1)$ & $(2)$ & (3) & (4) & (5) \\
\hline $\mathrm{PM}_{10}$ & 35.3 & 35.9 & -0.6 & $20.5^{*}$ & $17.8^{*}$ \\
\hline Market value (2000\$) & 162,108 & & & $-11,835$ & \\
\hline Annual rent $(2000 \$)$ & & 7,587 & & & 483 \\
\hline Household income (2000\$) & 41,179 & 23,429 & $17,750 *$ & -395 & $6,584 *$ \\
\hline Percent of households with children under 18 & $32.7 \%$ & $33.9 \%$ & -1.2 & 0.1 & 1 \\
\hline Percent of households with head over 65 & $31.1 \%$ & $15.9 \%$ & $15.2 *$ & 1 & -4.3 \\
\hline Percent of households with Black or Hispanic head & $16.6 \%$ & $34.8 \%$ & $-18.2^{*}$ & 1.9 & -6.2 \\
\hline Percent of households with high school graduate as head & $56.5 \%$ & $51.6 \%$ & $4.9 *$ & -2.5 & $-7.4^{*}$ \\
\hline Percent of households with college graduate as head & $27.7 \%$ & $23.9 \%$ & $3.8 *$ & 3.5 & $9.6^{*}$ \\
\hline Number of bedrooms & 2.9 & 1.7 & $1.2^{*}$ & $-0.1 *$ & -0.1 \\
\hline Number of bathrooms & 1.6 & 1.1 & $0.5 *$ & $0.1^{*}$ & 0 \\
\hline Square feet & 2005 & 1037 & $967.8^{*}$ & $-409.6 *$ & 209.7 \\
\hline Percent of units with a dishwasher & $51.2 \%$ & $21.3 \%$ & $29.9 *$ & $8.1^{*}$ & 3.7 \\
\hline Percent of units with central AC & $37.7 \%$ & $18.9 \%$ & $18.8^{*}$ & $6.9 *$ & 3.6 \\
\hline Percent of units under rent control & & $8.5 \%$ & & & $17.8^{*}$ \\
\hline Change in log market value, 1987-1989 & -0.024 & & & -0.041 & \\
\hline Change in log annual rent, 1987-1989 & & -0.026 & & & -0.031 \\
\hline Change in household income, 1987-1989 & 2,667 & 2,446 & 221 & 2,446 & 2,197 \\
\hline Percent of units with turnover, 1987-1989 & $7.4 \%$ & $39.7 \%$ & $-32.3 *$ & 2 & -4 \\
\hline
\end{tabular}


Table 2: IV first difference results for owner occupied units

\begin{tabular}{|c|c|c|c|c|c|}
\hline \multirow[b]{3}{*}{ First Stage } & \multicolumn{5}{|c|}{ Interval } \\
\hline & 2 & 4 & 6 & 8 & 10 \\
\hline & & & & & \\
\hline \multirow[t]{2}{*}{ Monitor non-attainment } & -5.75 & -12.10 & -19.21 & -22.03 & -16.22 \\
\hline & $(0.83)^{* * *}$ & $(1.44)^{* * *}$ & $(2.23) * * *$ & $(2.53) * * *$ & $(3.51)^{* * *}$ \\
\hline F-stat & 47.80 & 70.47 & 74.11 & 75.61 & 21.36 \\
\hline \multicolumn{6}{|l|}{ Second Stage } \\
\hline \multirow[t]{2}{*}{$\Delta \mathrm{PM}_{10}(1 / 100)$} & -0.66 & -1.01 & -0.59 & -0.83 & -1.39 \\
\hline & $(0.28)^{* *}$ & $(0.32)^{* * *}$ & $(0.3)^{* *}$ & $(0.39)^{* *}$ & $(0.7)^{* *}$ \\
\hline R-squared & 0.001 & 0.007 & 0.010 & 0.070 & 0.099 \\
\hline Observations & 17485 & 8961 & 5276 & 2972 & 1700 \\
\hline
\end{tabular}

Notes: The dependent variable in the first stage is the change in annual PM10 concentrations, and the dependent variable in the second stage is the change in the natural log of house value. Each regression uses the full set of controls listed in the Data Appendix. Standard errors are shown in parentheses and are estimated using the Eicker-White formula to correct for heteroskedasticity and are clustered at the monitor level. *, ** and *** indicate significance at $10 \%, 5 \%$ and $1 \%$, respectively. 
Table 3: IV first difference results for renter occupied units

\begin{tabular}{|c|c|c|c|c|c|}
\hline \multirow{3}{*}{ First Stage } & \multicolumn{5}{|c|}{ Interval } \\
\hline & 2 & 4 & 6 & 8 & 10 \\
\hline & & & & & \\
\hline \multirow[t]{2}{*}{ Monitor non-attainment } & -4.75 & -12.34 & -15.83 & -17.53 & -13.23 \\
\hline & $(0.86)^{* * *}$ & $(1.12)^{* * *}$ & $(2.3)^{* * *}$ & $(2.61)^{* * *}$ & $(3.18) * * *$ \\
\hline F-stat & 30.44 & 122.36 & 47.46 & 45.23 & 17.34 \\
\hline \multicolumn{6}{|l|}{ Second Stage } \\
\hline \multirow[t]{2}{*}{$\Delta \mathrm{PM}_{10}(1 / 100)$} & -0.21 & -0.25 & -0.76 & -1.18 & -2.03 \\
\hline & $(0.35)$ & $(0.2)$ & $(0.32)^{* *}$ & $(0.58)^{* *}$ & $(0.98) * *$ \\
\hline R-squared & 0.032 & 0.088 & 0.147 & 0.110 & 0.041 \\
\hline Observations & 15464 & 7394 & 4148 & 2166 & 1022 \\
\hline
\end{tabular}

Notes: The dependent variable in the first stage is the change in annual PM10 concentrations, and the dependent variable in the second stage is the change in the natural log of annual rent. Each regression uses the full set of controls listed in the Data Appendix. Standard errors are shown in parentheses and are estimated using the Eicker-White formula to correct for heteroskedasticity and are clustered at the monitor level. *, ** and *** indicate significance at $10 \%, 5 \%$ and $1 \%$, respectively. 
Table 4: Results of IV lagged specification

\begin{tabular}{|c|c|c|}
\hline & own & rent \\
\hline \multicolumn{3}{|l|}{ First Stages } \\
\hline F-stat predicting $\Delta \mathrm{PM}_{10}(1 / 100)$ & 16.71 & 13.55 \\
\hline F-stat predicting lagged $\Delta \mathrm{PM}_{10}(1 / 100)$ & 13.05 & 8.90 \\
\hline \multicolumn{3}{|l|}{ Second Stage } \\
\hline$\Delta \mathrm{PM}_{10}(1 / 100)$ & $\begin{array}{c}-1.38 \\
(0.62)^{* *}\end{array}$ & $\begin{array}{c}0.69 \\
(0.77)\end{array}$ \\
\hline Lagged $\Delta \mathrm{PM}_{10}(1 / 100)$ & $\begin{array}{c}0.20 \\
(0.75)\end{array}$ & $\begin{array}{c}-1.18 \\
(0.92)\end{array}$ \\
\hline
\end{tabular}

Notes: The two-year interval data is used, and only unit-intervals with prior interval data are included. Each column reports results from three regressions: two first stage regressions, one predicting $\Delta \mathrm{PM}_{10}$ and the other predicting lagged $\Delta \mathrm{PM}_{10}$, and a single second stage regression. The instruments are monitor non-attainment status for the current interval and monitor nonattainment status for the lagged interval. Each regression uses the full set of controls listed in the Data Appendix. Standard errors are shown in parentheses and are estimated using the EickerWhite formula to correct for heteroskedasticity and are clustered at the monitor level. *, ** and *** indicate significance at $10 \%, 5 \%$ and $1 \%$, respectively. 
Table 5: Testing hypotheses for delayed rental capitalization

\begin{tabular}{lccccc}
\hline \hline & \multicolumn{7}{c}{ Interval } \\
\cline { 2 - 6 } & \multicolumn{7}{c}{4} & 4 & 6 & 10 \\
\cline { 2 - 6 } Panel A: Exclude rent controlled units & -0.80 & -1.19 & -1.99 \\
$\Delta \mathrm{PM}_{10}(1 / 100)$ & -0.40 & -0.50 & $(0.36)^{* *}$ & $(0.58)^{* *}$ & $(0.98)^{* *}$
\end{tabular}

Panel B: Include only unit-interval observations with turnover

\begin{tabular}{cccccc}
\hline$\Delta \mathrm{PM}_{10}(1 / 100)$ & -0.16 & -0.08 & -0.89 & -1.19 & -2.12 \\
& $(0.5)$ & $(0.36)$ & $(0.35)^{* * *}$ & $(0.57)^{* *}$ & $(1)^{* *}$
\end{tabular}

Panel C: Geographic overlap for owner and renter units

$\begin{array}{cccccc}\Delta \mathrm{PM}_{10}(1 / 100) & -0.18 & -0.25 & -0.76 & -0.87 & -1.71 \\ & (0.36) & (0.2) & (0.33)^{* *} & (0.58) & (0.94)^{*}\end{array}$

Panel D: Reweight by probability of owning based on occupant characteristics

$\begin{array}{cccccc}\Delta \mathrm{PM}_{10}(1 / 100) & -0.24 & -0.12 & -0.58 & -1.10 & -1.82 \\ & (0.37) & (0.20) & (0.31)^{*} & (0.50)^{* *} & (0.85)^{* *}\end{array}$

Panel E: Reweight by probability of owning based on occupant and housing characteristics

$\begin{array}{llllll}\Delta \mathrm{PM}_{10}(1 / 100) & -0.22 & -0.16 & -0.24 & -0.83 & -1.19 \\ & (0.33) & (0.21) & (0.47) & (0.56) & (1.02)\end{array}$

Panel F: De-trend using AHS-derived price index

\begin{tabular}{cccccc}
\hline$\Delta \mathrm{PM}_{10}(1 / 100)$ & -0.17 & -0.01 & -0.59 & -0.98 & -2.22 \\
& $(0.32)$ & $(0.19)$ & $(0.28)^{* *}$ & $(0.51)^{*}$ & $(0.99)^{* *}$ \\
\hline
\end{tabular}

Notes: Each coefficient comes from a separate regression, identical to those in Table 3, except for the sample. Sample sizes are censored to reduce disclosure risk. Standard errors are shown in parentheses and are estimated using the Eicker-White formula to correct for heteroskedasticity and are clustered at the monitor level. *, **, and $* * *$ indicate significance at $10 \%, 5 \%$ and $1 \%$, respectively. 
Table 6: IV first difference results for changes in turnover frequency and demographic characteristics of occupants for renter occupied units

\begin{tabular}{|c|c|c|c|c|c|}
\hline \multirow{3}{*}{ Panel A: Turnover } & \multicolumn{5}{|c|}{ Interval } \\
\hline & 2 & 4 & 6 & 8 & 10 \\
\hline & & & & & \\
\hline \multirow[t]{2}{*}{$\Delta \mathrm{PM}_{10}(1 / 100)$} & 0.52 & 1.57 & -3.33 & -3.85 & 0.56 \\
\hline & $(2.10)$ & $(0.91)$ & $(1.41)^{* *}$ & $(2.08)^{*}$ & $(5.29)$ \\
\hline Marginal effect (\%) & 0.20 & 0.58 & -1.11 & -1.14 & 0.13 \\
\hline \multicolumn{6}{|c|}{ Panel B: Presence of children under 18} \\
\hline \multirow[t]{2}{*}{$\Delta \mathrm{PM}_{10}(1 / 100)$} & -0.74 & -2.03 & -8.49 & -7.51 & -13.40 \\
\hline & $(4.13)$ & $(3.32)$ & $(3.63)^{* *}$ & $(3.69)^{* *}$ & $(4.55) * * *$ \\
\hline Marginal effect (\%) & -0.29 & -0.78 & -3.04 & -2.65 & -4.30 \\
\hline \multicolumn{6}{|c|}{ Panel C: Household head over the age of 65} \\
\hline \multirow[t]{2}{*}{$\Delta \mathrm{PM}_{10}(1 / 100)$} & 3.65 & 10.62 & 8.33 & 14.07 & N/A \\
\hline & $(8.73)$ & $(5.56)^{*}$ & $(5.54)$ & $(5.08) * * *$ & \\
\hline Marginal effect (\%) & 1.24 & 3.33 & 2.69 & 4.22 & \\
\hline \multicolumn{6}{|c|}{ Panel D: Household head Black or Hispanic } \\
\hline \multirow[t]{2}{*}{$\Delta \mathrm{PM}_{10}(1 / 100)$} & -3.90 & -0.88 & 4.26 & -8.81 & 0.81 \\
\hline & $(3.04)$ & $(2.27)$ & $(3.73)$ & $(3.98)^{*}$ & $(5.59)$ \\
\hline Marginal effect (\%) & -0.29 & -0.78 & -3.04 & -2.65 & -4.30 \\
\hline \multicolumn{6}{|c|}{ Panel E: Educational attainment } \\
\hline \multirow[t]{2}{*}{$\Delta \mathrm{PM}_{10}(1 / 100)$} & -2.22 & 1.14 & -4.67 & 0.88 & -2.03 \\
\hline & $(4.06)$ & $(1.81)$ & $(2.47)^{*}$ & $(3.34)$ & $(6.27)$ \\
\hline Marginal effect (\%) & -0.87 & 0.44 & -1.76 & 0.33 & -0.75 \\
\hline \multicolumn{6}{|c|}{ Panel F: Natural log of household income } \\
\hline \multirow[t]{2}{*}{$\Delta \mathrm{PM}_{10}(1 / 100)$} & 4.11 & -0.85 & -0.60 & 2.99 & -0.90 \\
\hline & $(2.08)^{* *}$ & $(1.00)$ & (1.52) & (1.91) & $(3.29)$ \\
\hline
\end{tabular}

Notes: Each coefficient represents a different regression. Each specification includes all covariates listed in the data appendix. For Panel A, the sample is the same as in Table 3, and the dependent variable is binary and equal to one if new occupants moved in to the unit at some point during the interval. For Panels B-F, samples include only unit-intervals that experienced turnover and where the demographic characteristic of choice changed. For Panels B-E, the dependent variable is binary and equals one if the unit gained in the given characteristic and equals zero if it lost. For example, if the out-moving occupant does not have children and the in-moving occupant does, then this would be coded as one. If both out- and in-moving occupants have children, then that unit-interval would be excluded from the sample. For Panel E, maximum educational attainment of all household heads is classified into high school dropout, high school graduate, and college graduate, and the dependent variable takes the value one if there is an increase in educational attainment along the lines of the three classifications (i.e., high school dropout moves out and high school grad moves in) and takes the value zero if educational attainment declines. The results shown in Panels A-E are estimated using an IV probit specification. Panel F is estimated using least squares, still in the IV first difference framework, as the dependent variable is continuous. "N/A" indicates that either the model did not converge or the first stage instrument had a F-stat less than 1.0. Sample sizes are censored to reduce disclosure risk. Standard errors are shown in parentheses and are estimated using the Eicker-White formula to correct for heteroskedasticity and are clustered at the monitor level. *, **, and *** indicate significance at $10 \%, 5 \%$, and $1 \%$, respectively. 